\title{
How Antipsychotics Work-From Receptors to Reality
}

\author{
Shitij Kapur, ${ }^{* \dagger}$ Ofer Agid, ${ }^{* \dagger}$ Romina Mizrahi, ${ }^{* \dagger}$ and Ming $\mathrm{Li}^{* \dagger}$ \\ *Centre for Addiction and Mental Health, Toronto, Canada M5S 1A1; ${ }^{\dagger}$ University of Toronto, Toronto, Canada; and \\ ${ }^{\ddagger}$ Department of Psychology, University of Nebraska-Lincoln, Lincoln, Nebraska 68588
}

\begin{abstract}
How does a small molecule blocking a few receptors change a patients' passionately held paranoid belief that the FBI is out to get him? To address this central puzzle of antipsychotic action, we review a framework linking dopamine neurochemistry to psychosis, and then link this framework to the mechanism of action of antipsychotics. Normal dopamine transmission has a role in predicting novel rewards and in marking and responding to motivationally salient stimuli. Abnormal dopamine transmission alters these processes and results in an aberrant sense of novelty and inappropriate assignment of salience leading to the experience of psychosis. Antipsychotics improve psychosis by diminishing this abnormal transmission by blocking the dopamine D2/3 receptor (not D1 or D4), and although several brain regions may be involved, it is suggested that the ventral striatal regions (analog of the nucleus accumbens in animals) may have a particularly critical role. Contrary to popular belief, the antipsychotic effect is not
\end{abstract}

delayed in its onset, but starts within the first few days. There is more improvement in the first 2 weeks, than in any subsequent 2 -week period thereafter. However, a simple organic molecule cannot target the complex phenomenology of the individual psychotic experience. Antipsychotics diminish dopamine transmission and thereby dampen the salience of the preoccupying symptoms. Therefore, in the initial stage of an antipsychotic response, the patients experience a detachment from symptoms, a relegation of the delusions and hallucinations to the back of their minds, rather than a complete erasure of the symptoms. Only with time, and only in some, via the mediation of new learning and plasticity, is there a complete resolution of symptoms. The implications of these findings for clinical care, animal models, future target discovery and drug development are discussed. Key Words: Schizophrenia, dopamine, antipsychotics, D2/3 receptors, salience.

\section{INTRODUCTION}

The introduction of chlorpromazine, in the 1950s, opened the era of modern antipsychotics, and since then dozens of antipsychotics have been developed and tested. In the 1960s, the idea that these antipsychotics were acting on the dopamine system took hold, a finding confirmed in the 1970s, and in the 1980s and 1990s the role of dopamine in psychosis was more firmly confirmed using neuroimaging studies.

Thus, whereas the role of dopamine in the biology of psychosis and a role for blocking dopamine receptors in the mechanism of antipsychotics is widely accepted-it still remains unclear how one links these neurobiological and pharmacological or "brain level" findings with the essentially phenomenological "mind-level" nature of psychosis and its resolution. In this article, we review a heuristically useful framework, derived from the role of

Address correspondence and reprint requests to Shitij Kapur, M.D., Ph.D., Centre for Addiction and Mental Health, 33 Russell Street, Toronto, Ontario, Canada M5S 2S1. E-mail: shitij_kapur@camh.net. dopamine in "salience" and psychosis, that allows one to bring together these different levels of analysis.

We begin with a brief review of the current accounts about the role of dopamine in emotion and behavior, with a particular emphasis on notions of reward, reward prediction, and salience. We use these concepts to then develop a framework that can potentially explain the phenomenology of psychosis and the phenomenological aspects of antipsychotic response. The framework then leads to a number of natural questions: Which dopamine receptors are relevant for antipsychotic response? How quickly after the onset of the biological action of antipsychotics does psychosis start improving? What do the patients' experience? How does this change the kind of animal models we seek?

The article is not a comprehensive review. Rather it represents a selective and limited review of data as they relate to the above questions with a particular bias toward the role of the dopamine system. The article is limited in that it focuses mainly on one neurotransmitter system (dopamine), whereas it is quite clear that other systems (e.g., glutamate, serotonin) are involved and 
interact; furthermore, it focuses on one major symptom type (psychosis), although it is well recognized that a number of other symptom types (cognitive, negative symptoms, affective) also carry major weight in the illness of schizophrenia. However, the effort here is to provide a coherent account within this focused area, rather than catalog a broad range of findings. As such, this article borrows from a number of previous articles and reviews published by our group and others, and where appropriate the reader is referred to these original articles for details and references.

\section{THE SALIENCE FRAMEWORK FOR PSYCHOSIS AND ANTIPSYCHOTICS?}

There is near universal agreement for a central role of dopamine in "reward" and "reinforcement"-although precisely what these terms mean and what dopamine contributes to their realization continues to be a matter of debate. These competing ideas are discussed in much greater detail in earlier articles ${ }^{1,2}$ - and are excerpted here from those texts.

One of the earliest scientifically supported ideas about the role of dopamine suggested that dopamine mediates hedonic pleasure. ${ }^{3}$ However, subsequent studies showed that dopamine is involved not only in appetitive events but also in aversive ones; ${ }^{4}$ and the release of dopamine often precedes the hedonic experience. ${ }^{5,6}$ To accommodate these and other findings, several complementary ideas have developed over time. At one level of analysis, the firing of the midbrain dopamine neurons is linked to "reward prediction." ${ }^{7,8}$ In this role, the dopamine system alters its firing when the animal encounters novel rewards in the environment or when well learnt associations are violated-i.e., when an unexpected new reward is found or an expected reward is omitted. ${ }^{7}$ This event-linked, self-terminating action occurs at subsecond time scale and has been demonstrated by measuring the burst firing of dopamine neurons and the release of phasic dopamine in the limbic regions. ${ }^{7,9}$ However, increases in dopamine of a much longer duration (minutes to hours) have been observed by microdialysis and have been linked to responses to rewarding stimuli. This longer time scale role of dopamine is thought to mediate the "motivational salience" of environmental stimuli and their associations. ${ }^{10,11}$ Motivational salience refers to the process whereby reward-associated stimuli come to be attention grabbing to the animal and become the focus of goal-directed behavior. This release of dopamine is thought to not only direct and accentuate the animals responses in the present situation, but also facilitates the "stamping in" of new associations and reward learning that guides future behavior. ${ }^{12}$ Thus, the dopamine system is involved in detecting new rewards in the environment, enhancing the animal's learning about the rewards and their associations, and driving goal-directed behavior. These reward-related functions, when combined with dopamine's well-established role in the motor system, allow for a seamless conversion of motivation to action. ${ }^{13}$

What then is the relationship of dopamine to schizophrenia? It is beyond the scope of this chapter to review this issue in great detail-the reader is referred to authoritative and comprehensive reviews of this matter. ${ }^{14-18}$ The themes that emerge are: 1) there is an aberrantly hyperdopaminergic state in schizophrenia; 2 ) this state is most closely tied to the expression of "positive" or "psychotic" symptoms; and 3) the hyperdopaminergia is perhaps the results of a dysfunction in genes and transmitters that indirectly regulate dopamine. How does one link the role of dopamine to the expression of psychosis?

Under normal circumstances, the context-driven activity of the dopamine system mediates the experience of novelty, the acquisition of appropriate motivational salience, and learning of appropriate associations. ${ }^{10,11,19,20}$ However, in the psychotic state, the abnormal context-independent firing and release to dopamine leads to the creation of aberrant novelty and salience. ${ }^{1}$ Figure 1 portrays this framework. In this framework, the cycle of events that begins with a series of genetic and environmental predispositions (FIG. 1) ${ }^{17,21}$ that result in a dysregulated dopamine system that fires and releases dopamine independent of cue and context (FIG. 1).

Kapur ${ }^{1}$ postulated that, during the prodrome to psychosis, this context-independent or context-inappropriate firing of dopamine neurons and dopamine release produces in patients an aberrant sense of novelty and salience (FIG. 1) $)^{2}$-a state well captures in these patients' accounts of the prodromal period: "I developed a greater awareness of ... my senses were sharpened. I became fascinated by the little insignificant things around me;" or "sights and sounds possessed a keenness that he had never experience before;" or "noticed things I had never noticed before." 1 Patients continue to accumulate these experiences of altered novelty and salience without a clear explanation for them. There is a gradually increasing sense of perplexity, confusion, and alterations in mood and behavior until it crystallizes into a delusion (FIG. 1). ${ }^{22,23}$

Delusions in this framework are a "top-down" cognitive explanation that the individual imposes upon these aberrant novelty/salience experiences in an effort to make sense of them (FIG. 1). Because the patient constructs the delusions, he or she is imbued with the psychodynamic themes and cultural context of the individual. Hallucinations in this framework are 


\section{From Dopamine To Salience To Psychosis - How Antipsychotics become Anti "psychotic"}

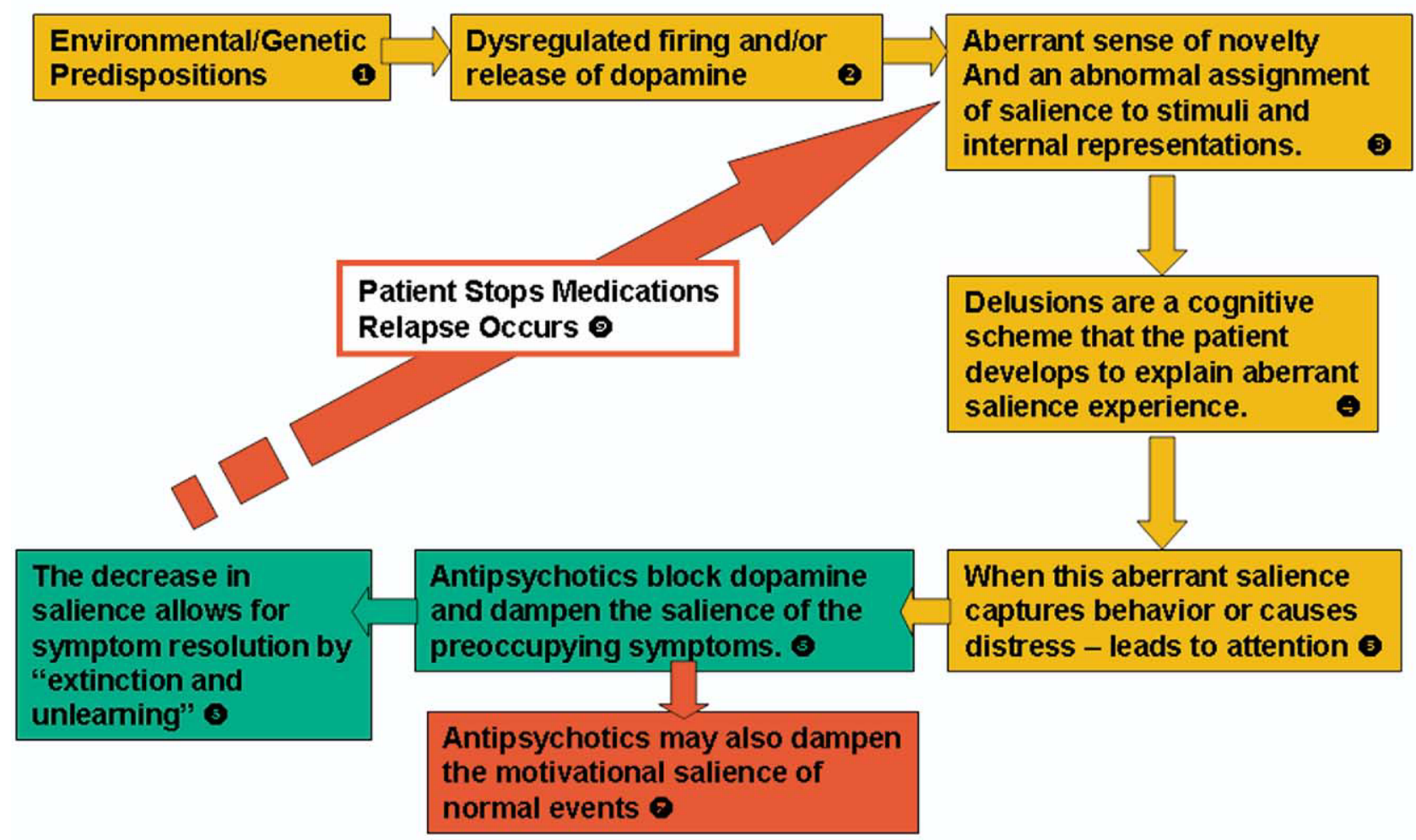

FIG. 1. A pictorial depiction of the hypothesis linking dopamine to psychosis and antipsychotics. The diagram shows a scheme for the chronological evolution of symptoms as a consequence of alterations in dopamine transmission and the effects of antipsychotics on these symptoms via blocking dopamine. A detailed explanation is provided in the text. The number in each box provides the relative order of the event in the sequence. Boxes show etiology and pathophysiology of symptoms and how aberrant dopamine transmission, via aberrant salience, leads to psychosis; boxes show the therapeutic and side effects of antipsychotic treatment as related to their actions on the dopamine system; and box depicts the common consequence of stopping antipsychotics, and how the resulting relapse leads to a re-entry into the cycle of events. Reproduced with permission from Kapur S. How antipsychotics become anti-"psychotic"from dopamine to salience to psychosis. Reprinted from Trends Pharmacol Sci 25:402-406. Copyright (C) 2004, with permission from Elsevier.

thought to arise from a conceptually similar processthey reflect the abnormal salience of the internal representations of percepts, language, and memories. ${ }^{1}$ Sooner or later, these delusions or hallucinations impact the patient's behavior-and this is typically when patients are brought to care and antipsychotics are administered (FIG. 1).

Antipsychotics, by blocking dopamine receptors, block the neurochemical milieu that was inciting aberrant salience, and instead provide a milieu wherein new aberrant salience is less likely to form and established aberrant salience are more likely to extinguish (FIG. 1). ${ }^{24-26}$ Thus, the disappearance of delusions and hallucinations is a dynamic process wherein antipsychotics block dopamine and thereby lessen the salience of the concerns, the patient works through their symptoms toward a psychological resolution (FIG. 1). ${ }^{26,27}$ However, antipsychotics attenuate salience across the board-and this may explain why patients find antipsychotics "dysphoric," and as a result noncompliance with these medications continues to be high (FIG. 1). ${ }^{1,28}$

Although antipsychotics block the expression of a disordered dopamine system, they do not reverse the underlying etiology or the disorder in the dopamine system. Thus, when antipsychotics are stopped (or sometimes even in their presence under periods of extreme stress or illicit drug use), the dopaminergic dysregulation remanifests itself (FIG. 1). The same ideas, schemes, and percepts that were previously part of the patient's symptoms become reinvested with salience once again and direct thought and behavior.

The ideas presented above are a heuristic framework rather than a single testable hypothesis. They serve to bring together ideas from different stages of the illness (prodromal, psychotic, residual) at different levels of 
analysis (neurochemical, psychological, pharmacological). The framework suggests a number of questions-we focus on a few selected ones.

\section{WHICH DOPAMINE RECEPTORS ARE CRITICAL FOR ANTIPSYCHOTIC RESPONSE?}

In the discussions above, we speak broadly of a "dopamine" system, although it is clear now that the dopamine system constitutes a number of midbrain neuronal collections that give rise to distinct projections to target regions in the striatum (nigrostriatal projections), limbic regions (mesolimbic projections), prefrontal cortex (mesocortical projections), and more recently a distinct pathway to the thalamus. ${ }^{29}$ Whereas all dopamine receptors link to $G$ proteins, they are further classified into two families: the D1-like receptor subfamily (including D1 and D5), which activates adenylate cyclase via their coupling to the $\mathrm{G} \alpha$ s subunits; and the D2-like receptor subfamily (including D2, D3, and D4 receptors), which de-

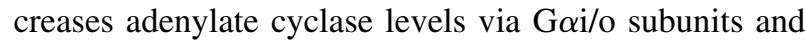
effects other proteins and ion channels via the release of $\mathrm{G} \alpha \beta \gamma$ subunits from receptor coupling. ${ }^{30,31}$ If the dopamine system is critical to antipsychotic action: Which dopamine projections? Which receptor subtypes?

The idea that dopamine receptors were involved in antipsychotic action can be traced back to the early observation that antipsychotics increased the turnover of monoamines, ${ }^{32}$ more specifically dopamine. ${ }^{33}$ This anticipated the discovery of a dopamine receptor, but it was not until the mid-70s that a precise receptor was identified. ${ }^{34-36}$ Although that receptor was originally christened as the "neuroleptic receptor"-with the differentiation of the D1 and D2 subfamilies, ${ }^{37}$ it became clear that the neuroleptic receptor was the D2 receptor. A central role for dopamine D2 receptor occupancy in antipsychotic action is now well established and has been documented in several positron emission tomography (PET) and single-photon emission tomography neuroimaging studies. ${ }^{38-41}$

The imaging studies have provided a more precise estimate of the relationship between the level of occupancy and outcome. Because there are a large number of papers, we can only summarize the conclusions here, and readers are referred to more detailed analyses elsewhere. ${ }^{41-44}$ All typical antipsychotics block dopamine D2 receptors, and it seems that blockade of $60-70 \%$ receptors is required to reach a threshold of antipsychotic activity, beyond which there is little evidence of enhanced antipsychotic efficacy. Doses of antipsychotics that lead to occupancies higher than $80 \%$, cause a much higher incidence of extrapyramidal side effects. The situation with atypical antipsychotics such as risperidone, olanzapine, and ziprasidone is generally similar, al- though some subtle differences (5-10\%) in thresholds for response and/or extrapyramidal side effects (EPS) between the typicals and these atypicals, cannot be ruled out because definitive head-to-head PET studies testing the thresholds have not been performed. Thus, this 65$80 \%$ "window" seems to cover the majority of the prescribed antipsychotics. However, two major deviations emerge.

Clozapine and quetiapine-two atypical antipsychotics with a lower incidence of EPS-are clinically effective at levels of D2 occupancy in the $40 \%$ range. ${ }^{45-47}$ Aripiprazole, on the other hand, seems to require greater than $85 \%$ D2 occupancy to be effective at clinical doses, and at the same time does not induce EPS despite almost complete saturation of dopamine D2 receptors. ${ }^{48}$ It has been proposed that even in these agents, blockade of dopamine D2 receptors is critical to their action-however, the lower affinity and faster dissociation of clozapine/quetiapine ${ }^{49}$ and the partial agonism of aripiprazole $^{50}$ allow them to achieve this blockade with apparently different levels of striatal D2 occupancy.

What about the other dopamine receptors? Given the prominent role for dopamine D1/5 receptor subfamily in reward and reward-related learning, it is quite plausible that dopamine D1 receptor antagonism contributes toward an antipsychotic effect. However, several small studies have failed to find evidence to that effect-and there is a suggestion that D1 blockade by itself may even exacerbate the psychotic symptoms. ${ }^{51-55}$ Although D1 antagonism seems an unlikely mechanism for an antipsychotic effect, its role as an adjuvant to D2 blockade ${ }^{56}$ and the potential role of D1 agonism are under active consideration. ${ }^{57}$

Data linking the effects of antipsychotics to dopamine $\mathrm{D} 2$ receptors is largely derived from in vitro and in vivo studies that use radioligands that do not specifically distinguish the D2 from the D3 and D4 subtype. This finding, coupled with the fact that the D3 subtype is preferentially distributed in the mesolimbic regions, has generated a lot of interest in the possibility that the therapeutic effects of antipsychotics may be D3 mediated, whereas the motor side effects may be the result of the nigrostriatal D2 blockade. ${ }^{58,59}$ Although the concept is attractive, there is no clinical test of this proposition as specific ligands for the dopamine D3 receptors are not widely available. At the same time, a number of indirect pieces of evidence argue against a role for the D3 receptors as the main locus of antipsychotic action ${ }^{60,61}$; some small-scale trials with initial agents have been negative ${ }^{62,63}$; and others suggest a role for D3 in the amelioration of negative and cognitive symptoms, rather than positive symptoms. ${ }^{59}$ Dopamine D4-another member of the D2 subfamily - was a subject of intense interest with regards to antipsychotic action because initial data suggested that the D4 receptors were elevated in schizo- 
phrenia and were related to efficacy in refractory patients. ${ }^{64-66}$ However, as more specific and selective agents have become available and have been tested in large-scale trials, agents with selective for ${ }^{67,68}$ and those with high affinity for the D4 receptor ${ }^{69}$ have been found to be devoid of antipsychotic efficacy.

Given the central importance of the D2 receptors, the question arises as to which target regions are most critical for the antipsychotic effect. Dopamine D2 receptors are observed in the nigrostriatal, mesolimbic, mesocortical, the newly defined thalamic, and the tubero-infudibular dopamine systems. ${ }^{29}$ In vitro studies fail to find structural or functional differences in the D2 receptors expressed across these regions. ${ }^{70}$ Whereas the dopamine D2 receptors express themselves in two alternative splice-variants (D2-short and D2-long), the differential anatomical distribution of these variants and its relevance for antipsychotic effect is not clear. ${ }^{71-73}$ One can exclude the tubero-infunidbular system on theoretical grounds (changes in prolactin are unlikely to be mediating antipsychotic effect) and on empirical grounds (prolactin effects and antipsychotic effects are uncorrelated $)^{74,75}$ - it is harder to choose between the other regions. The general strategies for addressing this question have involved measuring the regional impact of antipsychotics on D2 receptors in terms of receptor occupancy ${ }^{76}$ and functional markers, ${ }^{77}$ and relating these changes to the system level effects of antipsychotics in humans and animals.

Because the dopamine D2 receptors are similar across target regions and antipsychotics show similar penetration into the different brain regions (cf. pituitary system) ${ }^{78}$ as dose is increased, an effect of D2 blockade can be discerned in all the regions bearing D2 receptors. Thus, any claims to regional specificity are only relative in nature. When the effects of antipsychotics on the induction of immediate-early gene-product $\operatorname{FOS}^{79,80}$ and the depolarization of afferent dopamine neurons ${ }^{81-83}$ are measured, one observes a preferential effect in the mesolimbic dopaminergic regions (nucleus accumbens) as opposed to the nigrostriatal dopaminergic regions (dorsolateral caude-putamen). ${ }^{77}$ This focus on the mesolimbic dopamine system is theoretically plausible because the accumbens and the mesolimbic system in general are implicated in processing reward and motivational drives, ${ }^{12,84-86}$ processes that are critical to the generation of psychosis per the "salience" hypothesis. However, most of the preclinical data implicating the mesolimbic dopamine system are derived from studies in rodents wherein the mesocortical and the mesothalamic systems are underdeveloped in comparison to humans.

Of the human studies, most focus on "striatal" dopamine D2 receptor blockade, mainly because the first generation of imaging ligands gave good signals only from these regions. However, there is increasing interest in examining the effects of antipsychotics in the extrastriatal regions (mainly the thalamus, frontal, and temporal cortex). Some reports suggest that atypical antipsychotics (clozapine, olanzapine, sertindole, risperidone, and amisulpride) show a preferential blockade of the cortical dopamine D2 receptors compared with striatal dopamine D2 receptors. ${ }^{87,88}$ These reports have been questioned on methodological grounds, ${ }^{89}$ and there are an equal number of reports that fail to find such striatalextrastriatal differences. ${ }^{90-93}$ However, the question of greater interest is not the quantitative level of occupancy, but its clinical significance. A recent study by Agid et al. ${ }^{94}$ randomized patients to different levels of striatal and extrastriatal D2 occupancy as measured using 11Craclopride and 11C-FLB457, respectively, and observed that only the striatal, not the extrastriatal, D2 occupancy predicted response.

\section{HOW SOON AFTER DOPAMINE BLOCKADE DO ANTIPSYCHOTIC EFFECTS TAKE PLACE?}

Answer: "The onset of antipsychotic response is delayed." This idea of a "delayed onset" of antipsychotic action gained favor in the 1970s and is now firmly embedded in standard psychiatric textbooks. ${ }^{95-98}$ According to this hypothesis, there is a delay of 2-3 weeks from the initiation of medication to the onset of specific therapeutic benefits, even though dopamine receptor blockade is well established in the first few days. The "depolarization block" hypothesis has been proposed as an explanation for this delay. This hypothesis suggests that the effect of repeated antipsychotic administration on dopaminergic neurons in the brain is inactivation of firing and this inactivation takes place only after 3 weeks ( 21 days) of continuous treatment. It has been suggested that this 3-week period may explain the delay in onset of both the therapeutic effect and the neurological side effects of these drugs on schizophrenic patients. During the last two decades, more than 1050 articles have cited the papers describing the "depolarization block" hypothesis, ${ }^{99-109}$ attesting to the wide scientific acceptance of this idea.

Brain imaging has provided a direct window to the speed with which dopamine blockade is achieved in humans. Nordstrom et al. ${ }^{110}$ observed the speed-of-onset of dopamine blockade in response to receiving haloperidol, and Tauscher et al. ${ }^{93}$ have reported the effects of the atypical antipsychotic medications, risperidone and olanzapine. These studies unequivocally demonstrate a robust blockade of the dopamine system within hours of drug administration. Given that the blockade of the dopamine system is rather immediate, the idea of a "delayed onset" provides a particular stumbling block for 
the theory of a direct relationship between dopamine, dopamine blockade, psychosis, and antipsychotics.

The issue regarding the start of action of antipsychotics has been obscured by confusion between the "onset" (i.e., departure from baseline) and reaching a certain arbitrary threshold (say $30 \%$ or $40 \%$ improvement). Undoubtedly, reaching "full therapeutic effect" takes a number of weeks or months. ${ }^{111}$ This, by itself, does not imply a delay in the "onset" of action. In most areas of therapeutics (psychiatric or otherwise), medications take time to deliver their full benefits-only rarely does that imply a "delayed onset" of action. The "onset of action" of a drug usually takes place at an earlier point than reaching the full therapeutic effect of that drug. The earliest reports of chlorpromazine treatment in the $1950 \mathrm{~s}^{112,113}$ describe responses within days. Moreover, some of these 1950s studies report an early response that is over and above changes in sedation or level of agitation. ${ }^{14,115}$ Over the subsequent years, several others have raised the issue of an early onset of antipsychotic response (e.g., Stern et al., ${ }^{116,117}$ McDermott et al., ${ }^{118}$ Garver et al., ${ }^{19,120}$ and others), although the issue has never been systematically studied in large-scale and controlled trials.

A number of recent findings demonstrate that the onset of improvement is rather immediate after dopamine blockade. In a recent meta-analysis, ${ }^{121} 42$ published studies were identified which provide data on 7450 patients during the first 4 weeks of antipsychotic treatment. The percentage reductions in total scores of the Brief Psychiatric Rating Scale (BPRS) and the Positive and Negative Syndrome Scale (PANSS) were: $13.8 \%$ during the first week, $8.1 \%$ during the second week, $4.2 \%$ during the third week, and $4.7 \%$ during the fourth week. This pattern of "early" onset improvement was present even after the estimated effect of placebo was removed and when results were restricted to the psychotic subscales of the BPRS and the PANSS. This meta-analysis rejected the commonly held hypothesis that antipsychotic response is delayed. Rather, the findings suggest that the antipsychotic response starts in the first week of treatment and accumulates over time.

Whereas the above study describes the antipsychotic response within the first week, a recent report ${ }^{122}$ tested whether there is an onset of an antipsychotic effect within the first $24 \mathrm{~h}$. In a multicenter, double-blind, placebo-controlled study, 311 patients with a diagnosis of schizophrenia spectrum disorder were randomly assigned to receive $10 \mathrm{mg}$ i.m. of olanzapine, $7.5 \mathrm{mg}$ i.m. of haloperidol, or i.m. placebo. The olanzapine and haloperidol groups showed greater resolution of overall symptoms than the placebo group. An independent change in the psychotic symptoms was evident for both medications within the first $24 \mathrm{~h}$ of treatment. Most recently, Leucht et al. ${ }^{123}$ confirmed the "early onset of antipsychotic action hypothesis" in data from seven randomized trials including 1708 amisulpride treated patients with schizophrenia, and showed that the reduction of overall symptoms and positive psychotic symptoms until the second week of treatment was larger than the additional symptom reduction until the fourth week. Furthermore, they found that the majority of the improvement that the subjects will experience in the first year is already observed within the first few weeks of treatment.

Although these data lay to rest the traditional "delayed onset" hypothesis, it does not change the reality that, even after months of treatment, most patients with schizophrenia psychosis are not in full remission, but continue to harbor some elements of their psychotic ideas. So, what exactly about psychosis changes with antipsychotics?

\section{WHAT IS THE PATIENT'S EXPERIENCE WITH ANTIPSYCHOTICS?}

Although a considerable amount of scientific effort has been expended at describing how symptoms or clusters of symptoms change, ${ }^{124-127}$ almost all of this work entails the clinicians' assessment of how the drugs are impacting the patient. While some studies have focused on drug side-affects and their acceptability as well as studying the impact of drugs on the quality of life, ${ }^{128-135}$ little attention has been paid to how patients' experience the "antipsychotic" effect. In a recent study, we investigated a large group of chronically treated patients to ask what their medications did for their psychotic experiences using a structured questionnaire. ${ }^{136}$ A principal components analysis of the patients' responses revealed two major factors that explained $71 \%$ of the variance. The first factor included items such as "help me deal," "help me stop thinking" and "not bother"-a factor termed detachment. The second factor included the statements "change my mind" and "take away"-termed eradication. Chronically treated patients report that antipsychotics seem to "detach" them from their symptoms rather than "eradicate" them. When we gave the same questionnaire to a set of patients who had never experienced antipsychotics (neuroleptic naive) their response showed that they expected that the medications will both "detach" and "eradicate" symptoms. However, after the first 6 weeks of antipsychotic treatment, these neuroleptic-naive patients revised their opinion and gave a much higher rating to the ability of the antipsychotics to "detach" them from their symptoms, rather than "eradicate" them.

To follow up on these findings, we investigated in greater detail how the experience of psychosis changes after the beginning of antipsychotic medications. Using a newly developed scale, the Dimensions of Psychosis Experience Scale (DOPE-S), which identifies four different 
dimensions: cognitive and emotional preoccupation (CEP) with psychotic symptoms (delusions and/or hallucinations); behavioral impact (BI) of the symptoms; conviction (CO) in the symptoms; and ability to adopt an external perspective (EP) on their appropriateness-we followed drug-free patients that were started on antipsychotic medications for the first 6 weeks of antipsychotic treatment. ${ }^{137}$ The data showed that BI showed the greatest improvement (32\%) at 2 weeks; CEP responded next (19\%); the improvement in CO was limited (6\%); and EP showed no improvement, despite the conventional degree of improvement in PANSS positive subscale (17\%). After 6 weeks of antipsychotic treatment, the relative severity of the BI, CEP, and CO had become quite similar to the pattern observed in the chronically treated patients that was recorded in another separate group or chronically treated patients $(n=91)$ in whom the BI dimension had the lowest score.

These results are consistent with the view that the antipsychotics do not primarily take away the symptoms, they first reduce the impact of the symptoms by reducing the behavioral impact and the cognitive and emotional preoccupation with the psychotic experience. In light of recent evidence suggesting an earlier onset of therapeutic antipsychotic effects, ${ }^{121,138}$ our findings are of interest because they identify the particular aspects of psychosis (i.e., BI) on which antipsychotics appear to exert their earliest effects.

These results are also consistent with earlier intuitive observations made by Laborit and Huguenard, who reported in 1951 that patients given these drugs showed "désintéressement," a disinterest, in their surroundings. ${ }^{139,140}$ Whereas some patients do actually achieve complete resolution of their delusions and hallucinations with antipsychotic treatment, for many patients a detachment from their symptoms and a reduction in the BI and CEP is as good as resolution as antipsychotics can provide. This detachment may be necessary to allow patients to refrain from responding behaviorally, cognitively, and emotionally to aberrantly salient ideas or percepts (FIG. 1).

\section{IMPLICATIONS OF THESE DEVELOPMENTS FOR ANIMAL MODELS}

Animal models play an essential role in understanding the neurobiological and behavioral mechanisms of antipsychotics as well as for aiding drug discovery. Most of currently used models have high predictive validity for antipsychotic effect (e.g., conditioned avoidance response, catalepsy test, paw test, etc.) ${ }^{141-143}$ some possess construct validity (e.g., amphetamine-induced prepulse inhibition deficit and latent inhibition deficit, phencyclidine-induced social interaction deficit, etc. $)^{144-146}$ or neurobiological construct validity (e.g., neonatal hip- pocampal lesions, genetic models, etc.). ${ }^{147}$ However, none of these preparations provides a good model of the early onset, progressive enhancing effect of repeated antipsychotic treatment. Animal models that are based on the single acute antipsychotic treatment regimen (e.g., the usual use of latent inhibition ${ }^{148}$ and prepulse inhibition ${ }^{149}$ ) by definition, cannot model the progressive long-term antipsychotic effect or relapse. Other models (such as "depolarization block" 102 antipsychotic-induced Fos or FosB expressions; ${ }^{150}$ chronic prepulse inhibition model ${ }^{151}$ ) have used chronic treatment regimens but have often examined behavioral or physiological changes after the certain period of treatment has elapsed (e.g., $\sim 21$ days after the first drug administration), under the assumption of a "delayed onset" of antipsychotic action. Thus, it is unclear if these models capture the time course of antipsychotic response shown in humans.

The conditioned avoidance response (CAR) model has been used to study antipsychotic-like compounds for more than 50 years and has shown quite robust predictive and construct validity. ${ }^{152,153}$ In a typical experiment, a rat is placed in a two-compartment shuttle box and presented with a neutral conditioned stimulus (CS, e.g., white noise), followed by a mildly aversive unconditioned stimulus (US, e.g., footshock). The rat may escape the shock US by moving from one compartment to the other. Notably, after several CS-US pairings, the rat typically moves during the CS, thereby avoiding the US. Once acquired, avoidance responding is remarkably resistant to extinction. Animals will respond for hundreds of trials without receiving a single shock. ${ }^{156}$ Under certain circumstances, they may keep making avoidance responses even after they are prevented to respond to the CS. ${ }^{154,155}$ This persistent nature in the face of contradictory evidence renders avoidance responding a delusionlike phenomenon (a fixed false belief). In this sense, the CAR model may even possess some face validity of schizophrenic delusions and may explain why the anti"psychotic" property of a drug in this model is indexed by a selective disruption on this behavior.

Previous animal research has shown that all antipsychotics (typical and atypical, including the newer partial agonists such as aripiprazole) ${ }^{156}$ selectively disrupt avoidance responding at doses which do not alter unconditioned escape response. ${ }^{153}$ Other classes of psychotropic drugs (e.g., anxiolytics, barbiturates, MAOIs) do not possess this property. ${ }^{141,153}$ The potency of antipsychotics to inhibit avoidance responding is found to be positively correlated with their clinical potency against psychotic symptoms (predictive validity). ${ }^{141}$ Recent reports show that the level of dopamine D2 occupancy $(\sim 70 \%)$ that causes a disruption in avoidance responding in animals is in the same range as that found in schizophrenic patients that show effective antipsychotic response $^{157}$ - thus indicating a common underlying neuro- 
biological mechanism between CAR disruption in animals and antipsychotic response in humans (neurobiological construct validity). Finally, studies examining behavioral mechanisms responsible for CAR effects of antipsychotics suggest that the drugs may act by dampening the animals' response to the motivationally salient conditioned stimulus, ${ }^{11,158,159}$ consistent with the suggestion regarding their mode of action in patients (FIG. 1).

However, most implementations of CAR have focused on single-exposure studies with the main objective of identifying a "signal" of whether the drug is likely to be an antipsychotic or not. As in other models, little attention has been paid to the issue of onset, progressive increase, relapse, etc. More recently, we have observed that the disruptive effect of typical as well as atypical antipsychotics, which starts on day 1 of testing is progressively enhanced with each subsequent drug testing (an across-session decline) ${ }^{160}$ and the decline curve obtained with the CAR model was qualitatively similar to the symptom improvement observed in patients-consistent with the framework outlined in Figure 1. Interestingly, once the treatments were stopped, rats gradually reinstated their avoidance responding analogous to the gradual, but in most cases an inevitable, relapse observed in patients when the antipsychotics are stopped (FIG. 1). ${ }^{161}$ Given the selective nature of this review, we do not wish to claim primacy for the CAR model above other competing models. However, what is encouraging is that we have reached a stage where we can relate animal models to frameworks of human disease not only at a predictive, but, also at a neurobiological, behavioral and therapeutic level.

\section{ADVANCES, YES. BUT, STILL LOOKING FOR A BREAKTHROUGH}

Although one can take comfort that the science of antipsychotics is progressing steadily, it is still humbling to realize that 50 years after the introduction of the very first antipsychotic, we are still playing with the same main mechanism of action (D2), that the efficacy of the newer drugs is not notably better than those of the older ones, and the gold standard for efficacy (clozapine) is still a drug discovered by serendipity over four decades ago. ${ }^{162}$ Thus, whereas the field can claim many advances-the site of action of the current antipsychotics is known, can be visualized by PET imaging, can be used to predict dosing guidelines, time-course of onset is clearer, the impact on patients is more comprehensively understood - a genuine breakthrough has eluded us. What might such a breakthrough look like? In the view of the authors two domains look hopeful. A "clinical" breakthrough (likely driven by pharmacogenetics ${ }^{163}$ or imaging $^{43}$ ) would be the ability to predict, prospectively, which of the nearly 100 available antipsychotics will be optimal for a given patient. ${ }^{164,165}$ A "mechanism" breakthrough would entail bypassing the dopamine D2 receptor as the only target of efficacy-this may occur either through targeting other transmitter systems that regulate dopamine systems (e.g., glutamate, ${ }^{17}$ neurokinins ${ }^{166}$ etc.); or via acting directly on the intracellular messenger and trafficking systems that D2 receptors invoke to implement their actions (e.g., the newly discovered AktGSK pathway, ${ }^{167}$ the proteins that regulate the trafficking of D2 receptors, ${ }^{168,169}$ or mechanisms that alter receptor-receptor cross-talk ${ }^{170,171}$ etc.). Thus, while on the one hand, the future of this field, buoyed by advances in imaging, genetics, and molecular biology looks particularly ripe for a breakthrough in the next decade, our history of over half a century has a more humbling lesson to teach.

Acknowledgments: S.K.'s research in this area is supported by the Canada Research Chair in Schizophrenia and Therapeutic Neuroscience and grants from the Canadian Institutes of Health Research.

\section{REFERENCES}

1. Kapur S. Psychosis as a state of aberrant salience: a framework linking biology, phenomenology, and pharmacology in schizophrenia. Am J Psychiatry 160:13-23, 2003.

2. Kapur S. How antipsychotics become anti-"psychotic"-from dopamine to salience to psychosis. Trends Pharmacol Sci 25:402406, 2004.

3. Wise RA, Spindler J, deWit H, Gerberg GJ. Neuroleptic-induced "anhedonia" in rats: pimozide blocks reward quality of food. Science 201:262-264, 1978.

4. Salamone JD. The involvement of nucleus accumbens dopamine in appetitive and aversive motivation. Behav Brain Res 61:117133, 1994.

5. Wightman RM, Robinson DL. Transient changes in mesolimbic dopamine and their association with 'reward.' J Neurochem 82: 721-735, 2002.

6. Fibiger HC, Phillips AG. Reward, motivation, cognition: psychobiology of mesotelencephalic dopamine systems. In: Handbook of physiology - the nervous system (Mountcastle VB, ed), Vol 4, pp 647-675. Bethesda, MD: American Physiological Society, 1986.

7. Schultz W. Getting formal with dopamine and reward. Neuron 36:241-263, 2002.

8. Schultz W. Reward signaling by dopamine neurons. Neuroscientist 7:293-302, 2001.

9. Phillips PEM, Stuber GD, Heien MLAV, Wightman RM, Carelli RM. Subsecond dopamine release promotes cocaine seeking. $\mathrm{Na}$ ture 422:614-618, 2003.

10. Berridge KC. Pleasure, pain, desire and dread: hidden core processes of emotion. In: Well being: the foundations of hedonic psychology (Kahneman D, Diener E, Schwarz N, eds), pp 525557. New York: Russel Sage Foundation, 1999.

11. Berridge KC, Robinson TE. What is the role of dopamine in reward: hedonic impact, reward learning, or incentive salience? Brain Res Brain Res Rev 28:309-369, 1998.

12. Wise RA. Dopamine, learning and motivation. Nat Rev Neurosci 5:483-494, 2004.

13. Mogenson GJ, Jones DL, Yim CY. From motivation to action: functional interface between the limbic system and the motor system. Prog Neurobiol 14:69-97, 1980.

14. Davis KL, Kahn RS, Ko G, Davidson M. Dopamine in schizophrenia: a review and reconceptualization. Am J Psychiatry 148: 1474-1486, 1991. 
15. Seeman P, Kapur S. Schizophrenia: more dopamine, more D2 receptors. Proc Natl Acad Sci USA 97:7673-7675, 2000.

16. Abi-Dargham A. Do we still believe in the dopamine hypothesis? New data bring new evidence. Int $J$ Neuropsychopharmacol 7:S1-S5, 2004.

17. Harrison PJ, Weinberger DR. Schizophrenia genes, gene expression, and neuropathology: on the matter of their convergence. Mol Psychiatry 10:40-68, 2005.

18. Laruelle M, Abi-Dargham A. Dopamine as the wind of the psychotic fire: new evidence from brain imaging studies. $J$ Psychopharmacol 13:358-371, 1999.

19. Shizgal P. Neural basis of utility estimation. Curr Opin Neurobiol 7:198-208, 1997.

20. Heinz A. Anhedonia-a general nosology surmounting correlate of a dysfunctional dopaminergic reward system? Nervenarzt 70: 391-398, 1999.

21. Lewis DA, Levitt P. Schizophrenia as a disorder of neurodevelopment. Апnu Rev Neurosci 25:409-432, 2002.

22. Roberts G. The origins of delusion [see comments]. Br J Psychiatry 161:298-308, 1992.

23. Bowers MB Jr. Pathogenesis of acute schizophrenic psychosis. An experimental approach. Arch Gen Psychiatry 19:348-355, 1968.

24. Clody DE, Carlton PL. Stimulus efficacy, chlorpromazine, and schizophrenia. Psychopharmacology 69:127-131, 1980.

25. Miller R. The time course of neuroleptic therapy for psychosis: role of learning processes and implications for concepts of psychotic illness. Psychopharmacology 92:405-415, 1987.

26. Miller R. Hyperactivity of associations in psychosis. Aust $N Z$ J Psychiatry 23:241-248, 1989.

27. Chouinard G, Miller RA. Rating scale for psychotic symptoms (RSPS) part I: theoretical principles and subscale 1: perception symptoms (illusions and hallucinations). Schizophr Res 38:101122, 1999.

28. Gerlach J, Larsen EB. Subjective experience and mental sideeffects of antipsychotic treatment. Acta Psychiatr Scand Suppl 395:113-117, 1999.

29. Sanchez-Gonzalez MA, Garcia-Cabezas MA, Rico B, Cavada C. The primate thalamus is a key target for brain dopamine. $\mathrm{J} \mathrm{Neu}$ rosci 25:6076-6083, 2005.

30. Neve KA, Seamans JK, Trantham-Davidson H. Dopamine receptor signaling. J Recept Signal Transduct Res 24:165-205, 2004.

31. Missale C, Nash SR, Robinson SW, Jaber M, Caron MG. Dopamine receptors: from structure to function. Physiol Rev 78:189225, 1998.

32. Carlsson A, Lindquist M. Effect of chlorpromazine or haloperidol on the formation of 3-methoxytyramine and normetanephrine in mouse brain. Acta Pharmacol Toxicol 20:140-144, 1963.

33. van Rossum J. The significance of dopamine-receptor blockade for the action of neuroleptic drugs. In: Neuropsychopharmacology, Proceedings of the 5th Collegium Internationale Neuropsychopharmacologicum (Brill H, Cole J, Deniker P, Hippius H, Bradley P, eds), pp 321-329. Amsterdam: Excerpta Medica, 1967.

34. Seeman P, Chau-Wong M, Tedesco J, Wong K. Brain receptors for antipsychotic drugs and dopamine: direct binding assays. Proc Natl Acad Sci USA 72:4376-4380, 1975.

35. Seeman P, Lee T, Chau-Wong M, Wong K. Antipsychotic drug doses and neuroleptic/dopamine receptors. Nature 261:717-719, 1976.

36. Creese I, Burt, DR, Snyder SH. Dopamine receptor binding predicts clinical and pharmacological potencies of antischizophrenic drugs. Science 192:481-483, 1976.

37. Kebabian JW, Calne DB. Multiple receptors for dopamine. Nature 277:93-96, 1979.

38. Farde L, Wiesel FA, Halldin C, Sedvall G. PET-determination of central D1- and D2-dopamine receptor occupancy in neuroleptic treated schizophrenics. In: Clinical efficacy of positron emission tomography (Heiss W-D, Pawlick G, Herholz K, Wienhard K, eds), pp 213-219. Dordrecht, Holland: Martinus Nijhoff Publishers, 1987.

39. Nordstrom AL, Farde L, Wiesel FA, et al. Central D2-dopamine receptor occupancy in relation to antipsychotic drug effects-a double-blind PET study of schizophrenic patients. Biol Psychiatry 33:227-235, 1993.

40. Kapur S, Zipursky R, Jones C, Remington G, Houle S. Relationship between dopamine $\mathrm{D}(2)$ occupancy, clinical response, and side effects: a double-blind PET study of first-episode schizophrenia. Am J Psychiatry 157:514-520, 2000.

41. Kapur S, Mamo D. Half a century of antipsychotics and still a central role for dopamine D2 receptors. Prog Neuropsychopharmacol Biol Psychiatry 27:1081-1090, 2003.

42. Frankle WG, Gil R, Hackett E, et al. Occupancy of dopamine D-2 receptors by the atypical antipsychotic drugs risperidone and olanzapine: theoretical implications. Psychopharmacology 175: 473-480, 2004.

43. Tauscher J, Kapur S. Choosing the right dose of antipsychotics in schizophrenia: lessons from neuroimaging studies. CNS Drugs 15:671-678, 2001.

44. Nyberg S, Nilsson U, Okubo Y, Halldin C, Farde L. Implications of brain imaging for the management of schizophrenia. Int Clin Psychopharmacol 13[Suppl 3]:S15-S20, 1998.

45. Nordstrom AL, Farde L, Nyberg S, et al. D1, D2, and 5-HT2 receptor occupancy in relation to clozapine serum concentration: a PET study of schizophrenic patients [see comments]. Am J Psychiatry 152:1444-1449, 1995.

46. Kapur S, Zipursky R, Jones C, et al. A positron emission tomography study of quetiapine in schizophrenia: a preliminary finding of an antipsychotic effect with only transiently high dopamine D2 receptor occupancy. Arch Gen Psychiatry 57:553-559, 2000.

47. Kapur S, Seeman P. Does fast dissociation from the dopamine D2 receptor explain the action of atypical antipsychotics? A new hypothesis. Am J Psychiatry 158:360-369, 2001.

48. Yokoi F, Grunder G, Biziere K, et al. Dopamine D2 and D3 receptor occupancy in normal humans treated with the antipsychotic drug aripiprazole (OPC 14597): a study using positron emission tomography and [11C]raclopride. Neuropsychopharmacology 27:248-259, 2002.

49. Seeman P. Atypical antipsychotics: mechanism of action. Can J Psychiatry 47:27-38, 2002.

50. Burris KD, Molski TF, Xu C, et al. Aripiprazole, a novel antipsychotic, is a high-affinity partial agonist at human dopamine D2 receptors. J Pharmacol Exp Ther 302:381-389, 2002.

51. Karlsson P, Smith L, Farde L, et al. Lack of apparent antipsychotic effect of the D1-dopamine receptor antagonist SCH39166 in acutely ill schizophrenic patients. Psychopharmacology (Berl) 121:309-316, 1995.

52. Farde L, Nordstrom AL, Wiesel FA, et al. Positron emission tomographic analysis of central D1 and D2 dopamine receptor occupancy in patients treated with classical neuroleptics and clozapine: relation to extrapyramidal side effects. Arch Gen Psychiatry 49:538-544, 1992.

53. Den Boer JA, van Megen HJ, Fleischhacker WW, et al. Differential effects of the D1-DA receptor antagonist SCH39166 on positive and negative symptoms of schizophrenia. Psychopharmacology (Berl) 121:317-322, 1995.

54. de Beaurepaire R, Labelle A, Naber D, Jones BD, Barnes TR. An open trial of the D1 antagonist SCH 39166 in six cases of acute psychotic states. Psychopharmacology (Berl) 121:323-327, 1995.

55. Karle J, Clemmesen L, Hansen L, et al. NNC 01-0687, a selective dopamine D1 receptor antagonist, in the treatment of schizophrenia [letter]. Psychopharmacology (Berl) 121:328-329, 1995.

56. Tauscher J, Hussain T, Agid O, et al. Equivalent occupancy of dopamine D-1 and D-2 receptors with clozapine: differentiation from other atypical antipsychotics. Am J Psychiatry 161:16201625, 2004.

57. Abi-Dargham A, Moore H. Prefrontal DA transmission at D-1 receptors and the pathology of schizophrenia. Neuroscientist 9:404-416, 2003

58. Joyce J. Dopamine D3 receptor as a therapeutic target for antipsychotic and antiparkinsonian drugs. Pharmacol Therapeut 90: 231-259, 2001

59. Joyce JN, Millan MJ. Dopamine D3 receptor antagonists as therapeutic agents. Drug Discov Today 10:917-925, 2005.

60. Ralph RJ, Varty GB, Kelly MA, et al. The dopamine D2, but not D3 or D4, receptor subtype is essential for the disruption of 
prepulse inhibition produced by amphetamine in mice. J Neurosci 19:4627-4633, 1999.

61. Remington G, Kapur S. SB-277011 GlaxoSmithKline. Curr Opin Investig Drugs 2:946-949, 2001.

62. Lecrubier Y. Partial D3 receptor agonist in schizophrenia. J Euro College Neuropsychopharmacol 13:S167-S168, 2003.

63. Lahti AC, Weiler M., Carlsson A, Tamminga CA. Effects of the D3 and autoreceptor-preferring dopamine antagonist (+)-UH232 in schizophrenia. J Neural Transm 105:719-734, 1998.

64. Seeman P, Vantol HHM. Dopamine D4-like receptor elevation in schizophrenia: Cloned D2 and D4 receptors cannot be discriminated by raclopride competition against [H-3]nemonapride. J Neurochem 64:1413-1415, 1995.

65. Seeman P, Guan HC, VanTol, HH. Dopamine D4 receptors elevated in schizophrenia [see comments]. Nature 365:441-445, 1993.

66. Seeman P. Dopamine receptor sequences. Therapeutic levels of neuroleptics occupy D2 receptors, clozapine occupies D4. Neuropsychopharmacology 7:261-284, 1992.

67. Corrigan MH, Gallen CC, Bonura ML, Merchant KM. Effectiveness of the selective D-4 antagonist sonepiprazole in schizophrenia: a placebo-controlled trial. Biol Psychiatry 55:445-451, 2004.

68. Bristow LJ, Kramer MS, Kulagowski J, et al. Schizophrenia and L-745, 870, a novel dopamine D4 receptor antagonist. Trends Pharmacol Sci 18:186-188, 1997.

69. Truffinet P, Tamminga CA, Fabre LF, et al. Placebo-controlled study of the D4/5-HT2A antagonist fananserin in the treatment of schizophrenia. Am J Psychiatry 156:419-425, 1999

70. Seeman P, Ulpian C. Neuroleptics have identical potencies in human brain limbic and putamen regions. Eur J Pharmacol 94: 145-148, 1983.

71. Leysen JE, Gommeren W, Mertens J, et al. Comparison of in vitro binding properties of a series of dopamine antagonists and agonists for cloned human dopamine D2S and D2L receptors and for D2 receptors in rat striatal and mesolimbic tissues, using [125I] 2'-iodospiperone. Psychopharmacology 110:27-36, 1993.

72. Usiello A, Baik JH, Rouge-Pont F, et al. Distinct functions of the two isoforms of dopamine D2 receptors. Nature 408:199-203, 2000.

73. Centonze D, Usiello A, Gubellini P, et al. Dopamine D2 receptormediated inhibition of dopaminergic neurons in mice lacking D2L receptors. Neuropsychopharmacology 27:723-726, 2002.

74. Bressan RA, Erlandsson K, Spencer EP, Ell PJ, Pilowsky LS. Prolactinemia is uncoupled from central D-2/D-3 dopamine receptor occupancy in amisulpride treated patients. Psychopharmacology 175:367-373, 2004.

75. Goodnick PJ, Rodriguez L, Santana O. Antipsychotics: impact on prolactin levels. Expert Opin Pharmacother 3:1381-1391, 2002.

76. Schotte A, Janssen PF, Gommeren W, et al. Risperidone compared with new and reference antipsychotic drugs: in vitro and in vivo receptor binding. Psychopharmacology 124:57-73, 1996.

77. Arnt J, Skarsfeldt T. Do novel antipsychotics have similar pharmacological characteristics? A review of the evidence. Neuropsychopharmacology 18:63-101, 1998.

78. Kapur S, Langlois X, Vinken P, et al. The differential effects of atypical antipsychotics on prolactin elevation are explained by their differential blood-brain disposition: a pharmacological analysis in rats. J Pharmacol Exp Ther 302:1129-1134, 2002.

79. Robertson GS, Fibiger HC. Neuroleptics increase c-fos expression in the forebrain: contrasting effects of haloperidol and clozapine. Neuroscience 46:315-328, 1992.

80. Robertson GS, Matsumura H, Fibiger HC. Induction patterns of Fos-like immunoreactivity in the forebrain as predictors of atypical antipsychotic activity. J Pharmacol Exp Ther 271:10581066, 1994.

81. Grace AA, Bunney BS, Moore H, Todd CL. Dopamine-cell depolarization block as a model for the therapeutic actions of antipsychotic drugs. Trends Neurosci 20:31-37, 1997.

82. Skarsfeldt T. Differential effects of repeated administration of novel antipsychotic drugs on the activity of midbrain dopamine neurons in the rat. Eur J Pharmacol 281:289-294, 1995.

83. Skarsfeldt T. Differential effects after repeated treatment with haloperidol, clozapine, thioridazine and tefludazine on SNC and VTA dopamine neurones in rats. Life Sci 42:1037-1044, 1988.

84. Fibiger HC, Phillips AG. Mesocorticolimbic dopamine systems and reward. Ann NY Acad Sci 537:206-215, 1988.

85. Ettenberg A. Dopamine, neuroleptics and reinforced behavior. Neurosci Biobehav Rev 13:105-111, 1989.

86. Wise RA. Brain reward circuitry: insights from unsensed incentives. Neuron 36:229-240, 2002.

87. Bigliani V, Mulligan RS, Acton PD, et al. Striatal and temporal cortical D2/D3 receptor occupancy by olanzapine and sertindole in vivo: a. Psychopharmacology (Berl) 150:131-140, 2000.

88. Xiberas X, Martinot JL, Mallet L, et al. Extrastriatal and striatal $\mathrm{D}(2)$ dopamine receptor blockade with haloperidol or new antipsychotic drugs in patients with schizophrenia. Br J Psychiatry 179:503-508, 2001.

89. Olsson H, Farde L. Potentials and pitfalls using high affinity radioligands in PET and SPET determinations on regional drug induced D2 receptor occupancy-a simulation study based on experimental data. Neuroimage 14:936-945, 2001.

90. Talvik M, Nordstrom AL, Nyberg S, et al. No support for regional selectivity in clozapine-treated patients: a PET study with [(11)C]raclopride and [(11)C]FLB 457. Am J Psychiatry 158: 926-930, 2001.

91. Yasuno F, Suhara T, Okubo Y, et al. Dose relationship of limbiccortical D2-dopamine receptor occupancy with risperidone. Psychopharmacology (Berl) 154:112-114, 2001.

92. Kessler RM, Ansari MS, Riccardi P, et al. Occupancy of striatal and extrastriatal dopamine $\mathrm{D}(2) / \mathrm{D}(3)$ receptors by Olanzapine and Haloperidol. Neuropsychopharmacology 30:2283-2289, 2005.

93. Tauscher J, Jones C, Remington G, Zipursky RB, Kapur S. Significant dissociation of brain and plasma kinetics with antipsychotics. Mol Psychiatry 7:317-321, 2002.

94. Agid O, Mamo D, Zipursky RB, et al. Differentiating the roles of striatal vs. extrastriatal dopamine D2 receptors in antipsychotic response-a PET study. Schizophr Bull 31: 442, 2005.

95. Gelder MG, Lфpez-Ibor JJ, Andreasen N. New Oxford textbook of psychiatry. New York: Oxford University Press, Inc., 2000.

96. Grace AA, Bunney BS. Electrophysiological properties of midbrain dopamine neurons. In: Psychopharmacology, pp 163-177. New York: Raven Press, 1995.

97. Marder SV, Van-Kammen DP. Dopamine receptor antagonists. In: Comprehensive textbook of psychiatry (Kaplan HS, BJ, eds), Vol 2, pp 2356-2377. Baltimore: Lippincott Williams \& Wilkins, 2000.

98. Van-Kammen DP, SR. Serotonin dopamine antagonists. In: Comprehensive textbook of psychiatry (Kaplan HI, Sadock BJ, eds), Vol 2, pp 2455-2473. Baltimore: Lippincot, Williams \& Wilkins, 2000.

99. Brodie MS, Bunney EB. Serotonin potentiates dopamine inhibition of ventral tegmental area neurons in vitro. J Neurophysiol 76:2077-2082, 1996.

100. Grace AA. The depolarization block hypothesis of neuroleptic action: implications for the etiology and treatment of schizophrenia. J Neural Transm Suppl 36:91-131, 1992.

101. Grace AA. Cortical regulation of subcortical dopamine systems and its possible relevance to schizophrenia. J Neural Transm Gen Sect 91:111-134, 1993.

102. Grace AA, Bunney BS. Induction of depolarization block in midbrain dopamine neurons by repeated administration of haloperidol: analysis using in vivo intracellular recording. $J$ Pharmacol Exp Ther 238:1092-1100, 1986.

103. Harden DG, Grace AA. Activation of dopamine cell firing by repeated L-DOPA administration to dopamine-depleted rats: its potential role in mediating the therapeutic response to L-DOPA treatment. J Neurosci 15:6157-6166, 1995.

104. Hollerman JR, Abercrombie E, Grace AA. Electrophysiological, biochemical, and behavioral studies of acute haloperidol-induced depolarization block of nigral dopamine neurons. Neuroscience 47:589-601, 1992.

105. Hollerman JR, Grace AA. Acute haloperidol administration induces depolarization block of nigral dopamine neurons in rats after partial dopamine lesions. Neurosci Lett 96:82-88, 1989. 
106. Hollerman JR, Grace AA. Subthalamic nucleus cell firing in the 6-OHDA-treated rat: basal activity and response to haloperidol. Brain Res 590:291-299, 1992.

107. Moore H, Todd CL, Grace AA. Striatal extracellular dopamine levels in rats with haloperidol-induced depolarization block of substantia nigra dopamine neurons. J Neurosci 18:5068-5077, 1998.

108. Onn SP, Grace AA. Repeated treatment with haloperidol and clozapine exerts differential effects on dye coupling between neurons in subregions of striatum and nucleus accumbens. $J$ Neurosci 15:7024-7036, 1995.

109. Pucak ML, Grace AA. Evidence that systemically administered dopamine antagonists activate dopamine neuron firing primarily by blockade of somatodendritic autoreceptors. J Pharmacol Exp Ther 271:1181-1192, 1994.

110. Nordstrom AL, Farde L, Halldin C. Time course of D2-dopamine receptor occupancy examined by PET after single oral doses of haloperidol. Psychopharmacology (Berl) 106:433-438, 1992.

111. Baldessarini RJ, Cohen BM, Teicher M. Pharmacologic treatment. In: Schizophrenia: treatment of acute psychotic episodes (Levy ST, Ninan PT, eds), pp 61-118. Washington, DC: American Psychiatric Press, 1990.

112. Elkes J, Elkes C. Effects of chlorpromazine on the behaviour of chronically overactive psychotic patients. BMJ 4:560-565, 1954.

113. Winkelman NW. Chlorpromazine in the treatment of neuropsychiatric disorders. JAMA 155:18-21, 1954.

114. Delay J, Deniker P, Harl JM, Grasset A. [N-dimethylaminoprophylchlorophenothiazine (4560 RP) therapy of confusional states.]. Ann Med Psychol (Paris) 110:398-403, 1952.

115. Delay J, Deniker P, Harl JM. [Therapeutic use in psychiatry of phenothiazine of central elective action (4560 RP).]. Ann Med Psychol (Paris) 110:112-117, 1952.

116. Stern RG, Kahn RS, Davidson M, Nora RM, Davis KL. Early response to clozapine in schizophrenia. Am J Psychiatry 151: 1817-1818, 1994.

117. Stern RG, Kahn RS, Harvey PD, et al. Early response to haloperidol treatment in chronic schizophrenia. Schizophr Res 10: 165-171, 1993.

118. McDermott BE, Sautter FJ, Garver DL. Heterogeneity of schizophrenia: relationship to latency of neuroleptic response. Psychiatry Res 37:97-103, 1991.

119. Garver DL, Kelly K, Fried KA, Magnusson M, Hirschowitz J. Drug response patterns as a basis of nosology for the moodincongruent psychoses (the schizophrenias). Psychol Med 18: 873-885, 1988.

120. Garver DL, Steinberg JL, McDermott BE, et al. Etiologic heterogeneity of the psychoses: is there a dopamine psychosis? Neuropsychopharmacology 16:191-201, 1997.

121. Agid O, Kapur S, Arenovich T, Zipursky RB. Delayed-onset hypothesis of antipsychotic action: a hypothesis tested and rejected. Arch Gen Psychiatry 60:1228-1235, 2003.

122. Kapur S, Arenovich T, Agid O, et al. Evidence for onset of antipsychotic effects within the first 24 hours of treatment. Am J Psychiatry 162:939-946, 2005.

123. Leucht S, Busch R, Hamann J, Kissling W, Kane JM. Early-onset hypothesis of antipsychotic drug action: a hypothesis tested, confirmed and extended. Biol Psychiatry 57:1543-1549, 2005.

124. Casey JF, Bennett IF, Lindley CJ, et al. Drug therapy in schizophrenia. A controlled study of the relative effectiveness of chlorpromazine, promazine, phenobarbital, and placebo. Arch Gen Psychiatry 2:210-220, 1960.

125. Casey JF, Lasky JJ, Klett CJ, Hollister LE. Treatment of schizophrenic reactions with phenothiazine derivatives. A comparative study of chlorpromazine, triflupromazine, mepazine, prochlorperazine, perphenazine, and phenobarbital. Am J Psychiatry 117: 97-105, 1960.

126. Ceskova E, Svestka J. Double-blind comparison of risperidone and haloperidol in schizophrenic and schizoaffective psychoses. Pharmacopsychiatry 26:121-124, 1993.

127. Johnstone EC, Crow TJ, Frith CD, Carney MW, Price JS. Mechanism of the antipsychotic effect in the treatment of acute schizophrenia. Lancet 1:848-851, 1978.
128. Voruganti LN, Awad AG. Personal evaluation of transitions in treatment (PETiT):a scale to measure subjective aspects of antipsychotic drug therapy in schizophrenia. Schizophr Res 56:3746, 2002.

129. Kampman O, Lehtinen K, Lassila V, et al. Attitudes towards neuroleptic treatment: reliability and validity of the attitudes towards neuroleptic treatment (ANT) questionnaire. Schizophr Res 45:223-234, 2000.

130. Thompson K, Kulkarni J, Sergejew AA. Reliability and validity of a new Medication Adherence Rating Scale (MARS) for the psychoses. Schizophr Res 42:241-247, 2000.

131. Van Putten T, May PR, Marder SR, Wittmann LA. Subjective response to antipsychotic drugs. Arch Gen Psychiatry 38:187190, 1981.

132. Awad AG, Voruganti LN. Quality of life and new antipsychotics in schizophrenia. Are patients better off? Int J Soc Psychiatry 45:268-275, 1999.

133. Awad AG, Hogan TP, Voruganti LN, Heslegrave RJ. Patients' subjective experiences on antipsychotic medications: implications for outcome and quality of life. Int Clin Psychopharmacol 10[Suppl 3]:123-132, 1995.

134. Diamond R. Drugs and the quality of life: the patient's point of view. J Clin Psychiatry 46:29-35, 1985.

135. Hogan TP, Awad AG. Subjective response to neuroleptics and outcome in schizophrenia: a re-examination comparing two measures. Psychol Med 22:347-352, 1992.

136. Mizrahi R, Bagby RM, Zipursky RB, Kapur S. How antipsychotics work: the patients' perspective. Prog Neuropsychopharmacol Biol Psychiatry 29:859-864, 2005.

137. Mizrahi R, Bagby R, Remington G, Zipursky R, Kapur S. Understanding how antipsychotics improve psychosis: a multidimensional perspective. Schizophr Bull 31:497, 2005.

138. Abi-Dargham A, Rodenhiser J, Printz D, et al. Increased baseline occupancy of D2 receptors by dopamine in schizophrenia. Proc Natl Acad Sci USA 97:8104-8109, 2000.

139. Laborit H, Huguenard P. L' hibernation artificielle par moyen pharmacodynamique et physisques. Presse Med 59:1321, 1951.

140. Delay J, Deniker P, Harl JM. [Therapeutic method derived from hiberno-therapy in excitation and agitation states]. Ann Med Psychol (Paris) 110:267-273, 1952.

141. Arnt J. Pharmacological specificity of conditioned avoidance response inhibition in rats: inhibition by neuroleptics and correlation to dopamine receptor blockade. Acta Pharmacol Toxicol (Copenh) 51:321-329, 1982.

142. Ellenbroek BA., Peeters BW, Honig WM, Cools AR. The paw test: a behavioural paradigm for differentiating between classical and atypical neuroleptic drugs. Psychopharmacology (Berl) 93: 343-348, 1987.

143. Hoffman DC, Donovan H. Catalepsy as a rodent model for detecting antipsychotic drugs with extrapyramidal side effect liability. Psychopharmacology (Berl) 120:128-133, 1995.

144. Weiner I. The "two-headed" latent inhibition model of schizophrenia: modeling positive and negative symptoms and their treatment. Psychopharmacology (Berl) 169:257-297, 2003.

145. Johansson C, Jackson DM, Zhang J, Svensson L. Prepulse inhibition of acoustic startle, a measure of sensorimotor gating: effects of antipsychotics and other agents in rats. Pharmacol Biochem Behav 52:649-654, 1995.

146. Sams-Dodd F. Effects of dopamine agonists and antagonists on PCP-induced stereotyped behaviour and social isolation in the rat social interaction test. Psychopharmacology (Berl) 135:182-193, 1998.

147. Lipska BK. Using animal models to test a neurodevelopmental hypothesis of schizophrenia. J Psychiatry Neurosci 29:282-286, 2004.

148. Feldon J, Weiner I. The latent inhibition model of schizophrenic attention disorder. Haloperidol and sulpiride enhance rats' ability to ignore irrelevant stimuli. Biol Psychiatry 29:635-646, 1991.

149. Swerdlow NR, Geyer, MA. Clozapine and haloperidol in an animal model of sensorimotor gating deficits in schizophrenia. Pharmacol Biochem Behav 44:741-744, 1993.

150. Hiroi N, Graybiel AM. Atypical and typical neuroleptic treat- 
ments induce distinct programs of transcription factor expression in the striatum. J Comp Neurol 374:70-83, 1996.

151. Andersen MP, Pouzet B. Effects of acute versus chronic treatment with typical or atypical antipsychotics on d-amphetamine-induced sensorimotor gating deficits in rats. Psychopharmacology (Berl) 156:291-304, 2001.

152. Kilts CD. The changing roles and targets for animal models of schizophrenia. Biol Psychiatry 50:845-855, 2001.

153. Wadenberg ML, Hicks PB. The conditioned avoidance response test re-evaluated: is it a sensitive test for the detection of potentially atypical antipsychotics? Neurosci Biobehav Rev 23:851862,1999

154. Solomon RL, Kamin LJ, Wynne LC. Traumatic avoidance learning: the outcomes of several extinction procedures with dogs. $J$ Abnormal Social Psychol 48:291-302, 1953.

155. Baum M. Efficacy of response prevention (flooding) in facilitating the extinction of an avoidance response in rats: the effect of overtraining the response. Behav Res Ther 6:197-203, 1968

156. Reckless G, Natesan S, Parkes J, et al. Dissociation between blockade and functional antagonism of $\mathrm{D} 2$ receptors-comparing aripiprazole to other typical and atypical antipsychotics in animal models. Schizophr Bull 31:309, 2005.

157. Wadenberg ML, Kapur S, Soliman A, Jones C, Vaccarino F. Dopamine D2 receptor occupancy predicts catalepsy and the suppression of conditioned avoidance response behavior in rats. Psychopharmacology (Berl) 150:422-429, 2000.

158. Beninger RJ. The role of serotonin and dopamine in learning to avoid aversive stimuli. In: Aversion, avoidance, and anxiety: perspective on aversively motivated behavior (Archer T, Nilsson L, eds), pp 265-284. Hillsdale, NJ: Lawrence Erlbaum Associates, 1989

159. Li M, Parkes J, Fletcher PJ, Kapur S. Evaluation of the motor initiation hypothesis of APD-induced conditioned avoidance decreases. Pharmacol Biochem Behav 78:811-819, 2004.

160. Li M, Kapur S, Fletcher P. Examining the time course of anti- psychotic treatment in schizophrenia using conditioned avoidance responding model. In: Society for Neuroscience, Washington, DC, 2005.

161. Gilbert PL, Harris M, McAdams LA, Jeste DV. Neuroleptic withdrawal in schizophrenic patients. A review of the literature. Arch Gen Psychiatry 52:173-188, 1995.

162. Lieberman JA, Swartz MS, Rosenheck RA, et al. Effectiveness of antipsychotic drugs in patients with chronic schizophrenia. $N$ Engl J Med 353:1209-1223, 2005.

163. Malhotra AK, Murphy GM Jr, Kennedy JL. Pharmacogenetics of psychotropic drug response. Am J Psychiatry 161:780-796, 2004

164. Blasi G, Bertolino A. Imaging genomics and response to treatment with antipsychotics in schizophrenia. NeuroRx 3:117-130, 2006.

165. Stahl S. Finding what you are not looking for: strategies for developing novel treatments in psychiatry. NeuroRx 3:3-9, 2006

166. Sanger DJ. The search for novel antipsychotics: pharmacological and molecular targets. Expert Opin Ther Targets 8:631-641, 2004.

167. Beaulieu JM, Sotnikova TD, Marion S, et al. An Akt/ $\beta$-arrestin 2/PP2A signaling complex mediates dopaminergic neurotransmission and behavior. Cell 122:261-273, 2005.

168. Bartlett SE, Enquist J, Hopf FW, et al. Dopamine responsiveness is regulated by targeted sorting of D2 receptors. Proc Natl Acad Sci USA 102:11521-11526, 2005.

169. Lee SP, So CH, Rashid AJ, et al. Dopamine D1 and D2 receptor co-activation generates a novel phospholipase C-mediated calcium signal. J Biol Chem 279:35671-35688, 2004.

170. George SR, Ng GY, Lee SP, et al. Blockade of G protein-coupled receptors and the dopamine transporter by a transmembrane domain peptide: Novel strategy for functional inhibition of membrane proteins in vivo. J Pharmacol Exp Ther 307:481-489, 2003.

171. Simon AB, Gorman JM. Advances in the treatment of anxiety: targeting glutamate. NeuroRx 3:57-68, 2006. 